\title{
Life events and difficulties preceding stroke
}

\author{
Allan House, Martin Dennis, Liz Mogridge, Keith Hawton, Charles Warlow
}

\begin{abstract}
Life events and difficulties were recorded for the year before stroke, using a standardised semi-structured interview, in 113 surviving patients seen after their first ever in a lifetime stroke. An age and sex-matched control group $(n=109)$ was also interviewed about the preceding year. The stroke patients reported fewer non-threatening events and events with only a short-term threat, while difficulties were reported with equal frequency by the two groups. However, events which were severely threatening in the long-term were significantly more common in the stroke patients (in the $\mathbf{5 2}$ weeks before stroke $26 \%$ versus $13 \%$, odds ratio $2 \cdot 3,95 \%$ confidence interval $1 \cdot 1-4 \cdot 9)$. The increased rate was apparent throughout the year and not just in the weeks immediately before stroke onset. The number of stroke patients experiencing severe events in the follow up year fell to the level found in the control group. Recognised risk factors for stroke were found equally in those patients with and without severe events before onset, except that hypertension was rather less common in the patients who had experienced a severe event. It therefore appears that severe life events may be one of the determinants of stroke onset.
\end{abstract}

Writing in 1954, Ecker ${ }^{1}$ commented: "Preceding a cerebral stroke the patient has often suffered long-standing progressive difficulty in settling emotional problems. Immediately before the stroke he may have faced an overwhelming personal threat". Many people before and since have shared this view, but is it correct? In a recent review, Storey $^{2}$ concluded that there was little evidence to support the idea that emotional factors could be linked with long-term predisposition to stroke, and at least one study of Type A behaviour as a risk factor has produced a negative result. ${ }^{3}$ There are, however, a number of interesting anecdotal reports which suggest that severe threats may precipitate stroke, particularly caused by subarachnoid or primary intracerebral haemorrhage. ${ }^{14-7}$ Although the belief that stress causes stroke is common among the general public, most medical accounts of the risk factors for stroke either do not mention emotional stress or refer to it in passing as an intriguing but unsubstantiated possibility.
One reason for scepticism is the lack of methodologically sound studies to support the clinical accounts noted above.

The aim of this study was to examine the hypothesis that stroke is preceded by an increase in emotionally threatening experiences. In particular two types of stress were studied: the experience of highly threatening events in the period immediately before stroke, which the anecdotal accounts would predict as important; and the occurrence of events or difficulties with a more long-term threat, which research into the relationship between life events and other physical illnesses has indicated is important. We used a case-control design and a standardised method of identifying and rating stressful experiences which is based on a semi-structured interview of proven reliability. ${ }^{8} \mathrm{We}$ also examined the relationship between life events and difficulties and other risk factors for stroke.

\section{Subjects and methods}

The Oxfordshire Community Stroke Project The Oxfordshire Community Stroke Project (OCSP) has been described in detail elsewhere. ${ }^{9}$ Its basis is a register of all cases of first ever in a lifetime stroke and transient ischaemic attack occurring in a defined population of approximately 105000 , which is served by 50 general practitioners working in 10 group practices. All patients notified to the OCSP were assessed by a neurologist (MD, $\mathrm{CW}$ ). In addition to a full history and physical examination all patients had an ECG and blood tests to detect vascular risk factors, and in over $90 \%$ a CT brain scan was obtained. The final diagnosis of stroke was made at a weekly clinical consensus meeting, using a modification of the World Health Organisation definition. ${ }^{10}$

\section{Patients and controls}

Patients and controls were seen as part of a wider study of the psychiatric aspects of stroke, the details of which have been reported elsewhere. ${ }^{11}$

Stroke patients interviewed for this study had been notified about the project between 1 November 1985 and 30 November 1986, during which time 157 consecutive patients were seen and diagnosed as having had a first ever in a lifetime stroke. One hundred and twenty eight $(82 \%)$ of these patients survived to be interviewed for the life events study between 1 April and 31 December 1986. 
A control group was identified by taking a stratified random sample of the age-sex registers of four of the general practices from which the stroke patients were referred. The original sample $(n=141)$ was taken in 1986 , for use in a different study related to the OCSP, but for practical reasons interviewing for the present study was undertaken from April to December 1987. At this time 128 control subjects were available to be seen; one patient had had a stroke and was excluded, eight had died and four had left the area and were uncontactable. These 128 were approached through their general practitioners and asked to participate in a study of the effects of stress on physical health; 15 refused and two were too demented and infirm to participate, so that $111 / 128(87 \%)$ were eventually included. All controls were interviewed at home.

Satisfactory life events information was obtained for $113 / 128(88 \%)$ stroke patients. Reasons for inadequate interviews were confusion ( $n=8)$, dysphasia $(n=6)$, and refusal $(n=1)$. Of these patients $84 / 113$ were seen at one month after their stroke and 29 were seen for the first time six months after the stroke. Follow up interviews were possible with 109/ 113; two had died and two were now demented. These interviews were undertaken between November 1986 and December 1987, so that follow up interviewing of stroke patients overlapped with interviewing of the controls. For the controls, 109/111 were able to give adequate details of the preceding year; two lived alone and were unable to give reliable information. The demographic and social characteristics of the two groups are outlined in table 1 .

\section{The Life Events and Difficulties Schedule}

The subjects were interviewed using the Bedford College Life Events and Difficulties Schedule (LEDS) ${ }^{8}$ During the first stage of the interview key members of the subject's social network are identified, and then a systematic enquiry is made about experiences in an identified time period. By convention life "events" are episodic in nature: acute illnesses, accidents, court appearances, deaths of family, etc, while "difficulties" have persisted for more than four weeks, for example chronic ill health, protracted marital friction. Both events and difficulties are classified according to their content, for example, as health events, marital difficulties.

Once all events and difficulties have been identified, they are rated according to the severity of the threat they involve for the subject. Threat means the degree to which they might be expected to provoke emotional disturbance, and it is assessed on criteria that are called contextual by the Bedford College team. That is, the threat is rated not simply on the basis of the subject's report, nor on the basis of some predetermined rating scale, but according to a judgement about how threatening the average person would have found such an experience given the same circumstances. Events are rated on a 1-4 scale and difficulties
Table 1 Social characteristics of the stroke patients and controls who were able to complete the LEDS interview

\begin{tabular}{lll}
\hline & $\begin{array}{l}\text { Stroke } \\
\text { patients } \\
(n=113)\end{array}$ & $\begin{array}{l}\text { Controls } \\
(n=109)\end{array}$ \\
\hline $\begin{array}{l}\text { Age: mean (SD) } \\
\text { (range) }\end{array}$ & $\begin{array}{l}69 \cdot 9 \mathrm{yrs}(13 \cdot 7) \\
(18-96 \mathrm{yrs})\end{array}$ & $\begin{array}{l}69 \cdot 6 \mathrm{yrs}(11 \cdot 4) \\
(30-86 \mathrm{yrs})\end{array}$ \\
$\begin{array}{lll}\text { Sex: }(\mathrm{M}: \mathrm{F}) & 48: 65(0 \cdot 74: 1) & 43: 66(0 \cdot 65: 1)\end{array}$ \\
$\begin{array}{l}\text { Social class (Registrar-General) } \\
\text { I }\end{array}$ & $2(2 \%)$ & $4(4 \%)$ \\
II & $28(25 \%)$ & $33(30 \%)$ \\
III & $44(39 \%)$ & $36(33 \%)$ \\
IV & $31(27 \%)$ & $31(28 \%)$ \\
V & $8(7 \%)$ & $5(5 \%)$ \\
Household & & \\
Alone & $21(19 \%)$ & $23(21 \%)$ \\
Family & $85(76 \%)$ \\
Non family/institution & $6(5 \%)$ & $3(3 \%)$ \\
\hline
\end{tabular}

on a $1-6$ scale of threat, with 1 the most severe in both cases. In addition, events are rated according to whether they are threatening only in the short term, for example, many transient illnesses, or carry long term implications, for example, the death of a spouse, and according to whether they are specifically focussed on the subject or on other people close to the subject. Events which rate 1 or 2 on the 4 point scale for long-term threat, and which are focussed on the subject, are by convention known as "severe" events. For a detailed discussion of these issues, with illustrative cases, see Brown and Harris. ${ }^{8}$

The two interviewers (AH, LM) were trained in the reliable use of the LEDS, which involved attendance at an initial course organised by the Bedford College team, followed by supervision of the trainee's taped interviews. Thereafter, a comprehensive dictionary of rated events and difficulties, plus annotations on rating conventions, was used to ensure consistency.

Stroke patients were interviewed (by $\mathrm{AH}$ ) about life events and difficulties experienced in the 52 weeks before stroke, and were interviewed again approximately 12 months later about the 52 weeks after the stroke. The controls were interviewed once about the 52 weeks preceding interview (by $\mathrm{LM}$ ). To reduce bias resulting from the strokes and controls being interviewed by different people, all control interviews were audiotaped and re-rated by AH. Events and difficulties in both cases and controls were rated jointly by the two interviewers. During the course of the study events which raised particular rating problems were discussed with Tirril Harris at Bedford College, (who was unaware of the medical status of the subject whose events were being considered) for a decision about final ratings. As an independent measure of reliability, 50 events were presented to an independent rater with experience of the LEDS, who re-rated them without knowledge of whether they were events experienced by stroke patients or controls.

Although they are a major cause of stress in the lives of older people, events and difficulties involving the physical health of the subject 
Figure 1 Rate of reporting of life events of all types in the year before onset (strokes) or interview (controls). The year is divided into three week periods with lower numbers representing more recent weeks.

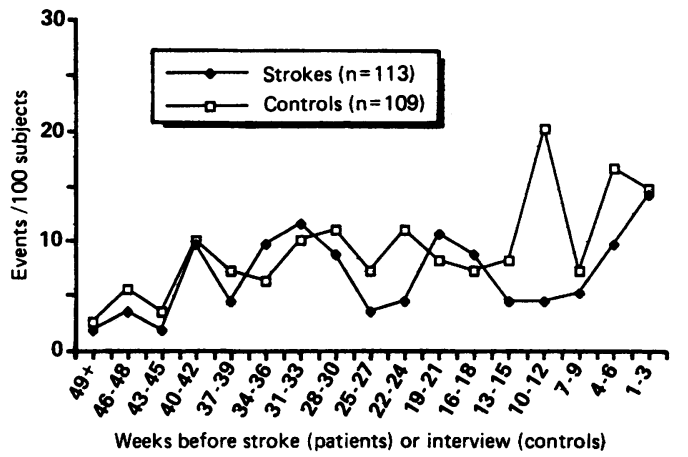

are excluded from the results here. We wanted to be sure that the events reported before stroke were unrelated to the presence of known medical risk factors for stroke, and not simply harbingers of the stroke itself. We therefore took the conservative approach of excluding all illness-related stressors from the analysis.

Odds ratios and confidence intervals were calculated according to the method suggested by Morris and Gardner. ${ }^{12}$

Table 2 Proportion of subjects who experienced at least one of the type of event or difficulty indicated, over 52 weeks before stroke or interview (for controls)

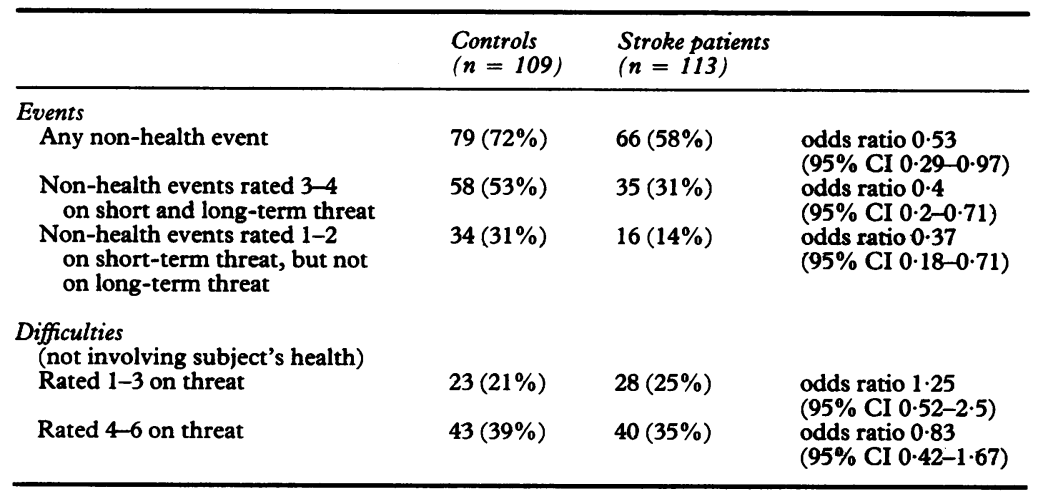

\section{Results}

Stroke patients and controls experienced similar rates of difficulties in the preceding year.

Both groups reported more life events for the weeks nearer the interview than they did for the weeks at the beginning of the study year (fig 1).

In the control group 79/109 (72\%) experienced at least one event in the 52 weeks, compared with $66 / 113(58 \%)$ stroke patients (odds ratio $1.995 \%$ CI 1.03-3.4). The controls reported more events with little or no threat and more events with short-term threat ratings of 1-2 but little or no long-term threat (table 2).

Events with high long-term threat ratings showed a different pattern. When only "severe" events were considered, there was a significant difference between the two groups; stroke patients experienced such events at about double the rate of controls. Table 3 shows the rate at which subjects experienced at least one severe event, for four different time periods before interview or stroke. For those subjects with more than one such event in the year, only that which was nearest to the stroke or interview was counted. When the relationship between timing of severe events and stroke onset was examined, the increase in severe events was not restricted to the immediate prestroke period (fig 2).

In the follow up period the proportion of patients experiencing life events fell considerably in the stroke group. In the 38 weeks poststroke $9 / 109(8 \%)$ experienced at least one "severe" event, and over the 52 weeks after stroke $16 / 109(15 \%)$ experienced such an event. A total of $72 / 109(66 \%)$ had at least one event of any sort during the 52 weeks poststroke. None of these rates differs significantly from those of the control group (tables 2 and 3 ).

An indication of the content of the severe events which preceded stroke is given in table 4. It is important to emphasise the high thresholds employed. Illnesses of others involved not just hospital admission but some serious long-term consequences for the subjects, for example, a spouse's stroke or diagnosis of cancer. Marital conflicts involved, for example, a separation or the spouse seeing a solicitor and not simply arguments. Not all deaths reported by the subject are rated here. Although loss of a pet is a recognised source of distress to most people, perhaps particularly in the elderly, it has not been rated as a "severe" event in previous life-events research, and was not therefore rated as a severe event in this study. Neither are most deaths of in-laws or friends unless the subject had an especially intimate relationship with them. Even death of a sibling is not rated this high unless the subject was in regular contact. A total of 34 deaths were reported by controls and 29 deaths were reported by stroke patients for the 52 weeks preceding interview, although in each case less than half met the criteria for severe events.

A corollary of the high threshold used in rating events as "severe" is that the rating is reliable between trained interviewers. When the consensus ratings used in the study were compared with the life-events ratings undertaken in the reliability study (by a rater without knowledge of the patient's clinical status), there was a high degree of agreement on whether an event was "severe" or not (kappa $=0 \cdot 80$ ).

Table 3 Proportion of subjects who experienced at least one severe event in the time period covered by the LEDS interview. Results shown for four time periods preceding stroke or interview (for controls); only the last event was counted for those with more than one

\begin{tabular}{lllll}
\hline & $\begin{array}{l}\text { Preceding } \\
\text { 52 weeks }\end{array}$ & $\begin{array}{l}\text { Preceding } \\
38 \text { weeks }\end{array}$ & $\begin{array}{l}\text { Preceding } \\
30 \text { weeks }\end{array}$ & $\begin{array}{l}\text { Preceding } \\
24 \text { weeks }\end{array}$ \\
\hline Stroke patients $(\mathrm{n}=113)$ & $29(26 \%)$ & $27(24 \%)$ & $25(22 \%)$ & $19(17 \%)$ \\
Controls $(\mathrm{n}=109)$ & $14(13 \%)$ & $13(12 \%)$ & $10(9 \%)$ & $9(8 \%)$ \\
& odds ratio $2 \cdot 3$ & odds ratio $2 \cdot 3$ & odds ratio 2.8 & odds ratio 2.2 \\
& $(95 \%$ CI $1 \cdot 1-4 \cdot 9)$ & $(95 \%$ CI $1 \cdot 1-5)$ & $(95 \%$ CI 1-2-6.4) & $(95 \%$ CI $0 \cdot 9-5 \cdot 7)$ \\
\hline
\end{tabular}


Figure 2 Proportion of subjects experiencing at least one severe event in each six week period of the interview year; lower numbers represent more recent weeks.

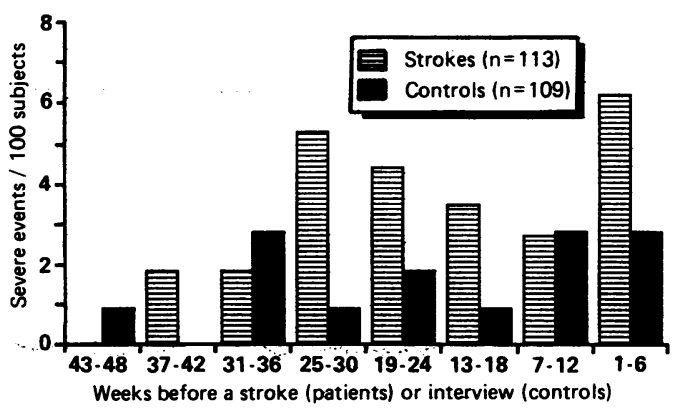

Table 4 Content of all severe events experienced by subjects in the 52 weeks before stroke or interview (for controls) NB some subjects experienced more than one event in the year

\begin{tabular}{lcc}
\hline & $\begin{array}{l}\text { Stroke } \\
\text { patients }\end{array}$ & Controls \\
\hline Deaths & 15 & 11 \\
Illness of others & 10 & 3 \\
Marital conflict/separation & 5 & 1 \\
Residence change (undesired) & 3 & 0 \\
Separations other than marital & 2 & 2 \\
Miscellaneous crises & 1 & 1 \\
& -39 & 18 \\
\hline
\end{tabular}

CT brain scans had been obtained in $112 / 113$ stroke patients. Severe events were reported by $3 / 12(25 \%)$ of those with definite haemorrhagic strokes (as diagnosed by CT scan) and 24/101 $(24 \%)$ of the remainder, where the CT scan showed an infarct or the scan was negative but the clinical diagnosis was of definite or probable cerebral infarction.

The relationship between the presence of a severe event preceding stroke, and other risk factors (as determined independently by the research neurologist at the time of notification), is shown in table 5 . The only positive finding was that those who reported a severe event were less likely to give a history of having been treated for hypertension at some time in their lives, or to have ever had a diastolic blood pressure above $100 \mathrm{~mm} \mathrm{Hg}$ recorded in their medical/general practice notes. Despite this finding there was no significant difference between those with and without severe events for the last blood pressure recorded in their medical notes before stroke onset (diastolic BP $\mathrm{t}=0.85$, df $113 ;$ systolic $\mathrm{BP} \mathrm{t}=1.57$; $\mathrm{df}=113$ both NS).

Table 5 Proportion of patients with various risk factors for stroke, according to whether they had a severe event in the 52 weeks before onset of stroke

\begin{tabular}{lcc}
\hline & $\begin{array}{c}\text { Severe event } \\
(n=29)\end{array}$ & $\begin{array}{c}\text { No severe event } \\
(n=84)\end{array}$ \\
\hline Age: mean (SD) & $67 \cdot 3(14 \cdot 9)$ & $\begin{array}{l}70 \cdot 8(13 \cdot 4) \\
\text { Sex: males (\%) }\end{array}$ \\
History of hypertension: & $11(41 \%)$ & $37(43 \%)$ \\
Systolic BP ever $>180$ & & \\
Diastolic BP ever $>100$ & $11(38 \%)$ & $41(48 \%)$ \\
Ever treated medically for hypertension & $7(24 \%)$ & $43(50 \%)^{\star}$ \\
Last recorded BP before stroke (mm Hg; mean (SD)) & $7(24 \%)$ & $44(51 \%) \dagger$ \\
Systolic blood pressure & & \\
Diastolic blood pressure & $147(25)$ & $156(31)$ \\
Previous myocardial infarct & $85(10)$ & $87(14)$ \\
Atrial fibrillation before stroke & $2(7 \%)$ & $10(12 \%)$ \\
Current smoker & $3(10 \%)$ & $12(14 \%)$ \\
Diabetes mellitus & $10(34 \%)$ & $17(20 \%)$ \\
\hline
\end{tabular}

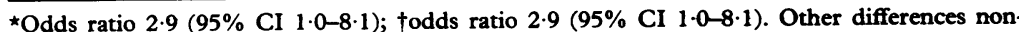
significant.
Finally, we made an attempt to determine whether refusal among the control group could have biased the sample in favour of those with fewer life events. This was difficult because by the nature of their refusal these people were unwilling to discuss recent experiences with members of the research team, and our only other source of information was what the general practitioner might know about the family. We identified $2 / 15$ refusers $(13 \%)$ who had definitely had family deaths within the year. Counting those as severe events does not materially change the results of the study. In fact statistically significant differences between the stroke patients and controls only disappear if we assume that 5/15 of the refusers in the control group had severe events in the 52 weeks before they would have been interviewed; an assumption for which we have no evidence.

\section{Discussion}

Our results provide interesting support for popular opinion about the cause of stroke, but could they be attributable to bias in the study?

First, the possibility of selection bias cannot be excluded absolutely, its main potential source being exclusions among the controls. The response rate among controls was high (87\% of those approached) and there are no $a$ priori grounds for believing that refusers would be different from the total group. ${ }^{12}$ In a community-based study of older people living at home, Murphy ${ }^{13}$ found a rate of severe events (excluding those involving the subject's health) almost identical to that among the responders in our control group. Bias in the stroke sample is far less likely. We contacted all survivors in a community-based sample, and had only one refusal; all other exclusions were for inability to participate due to cognitive impairment and dysphasia. Bias would only therefore have arisen if stress-related strokes were different in their severity, so that those who survived more than one month were more likely to report life events; we have no grounds for believing that to be the case.

Second, we considered the problem of observed bias, which could have arisen in this study from interviewers keen to find an association between stroke and stress, or from systematic bias resulting from stroke patients and controls being interviewed by different people. We attempted to minimise rating bias by audiotape recording and joint-rating of interviews, by the use of clearly defined criteria for making judgements about severity, and by recourse in borderline cases to an independent rater who was unaware of the medical status of the subject. In our study, as in others, ${ }^{18}$ the judgement about presence or absence of severe events has been shown to be highly reliable among trained interviewers. ${ }^{8}$

The main potential source of reporting bias in life events research is selective recall among patients who believe their condition to be stress-induced. A number of observations argue against such selective recall. The stroke patients actually reported fewer events overall, 
and fewer events with short-term threat (even for the six weeks immediately before onset) than the controls. This was probably because of poorer memory in the stroke patients, particularly since they were being asked (unlike the controls) about events experienced in a time period ending one to six months previously. Difficulties, which accord closely with lay ideas about stress, were no more common in the stroke group than in the controls. These findings would argue strongly against a general over-reporting of stress among the stroke patients. The threshold for severe events is high, that is they are extremely unpleasant experiences, so that it is unlikely that by their nature they would be under-reported by controls.

It might be argued that the severe events reported by the stroke patients are not of aetiological significance-that they are simply a corollary of the patients being more physically ill than the controls. The fall in the rate of severe events experienced by the. stroke patients in the follow up year does not support such a view. The relationship between severe events and stroke onset is not specific, however. Such events have been shown to precede the onset of depression, ${ }^{813}$ of presumably psychosomatic disorders such as "functional" abdominal pain, ${ }^{14}{ }^{15}$ and of a variety of physical disorders including myocardial infarction ${ }^{16} 17$ and relapse in multiple sclerosis. ${ }^{18}$ In fact it was because of the existing literature on the relationship between severe events and other illnesses that we examined their occurrence in this study.

Is there a plausible hypothesis for the way in which an effect of severe events on stroke onset might be mediated? The mechanism involved would probably be akin to one of those proposed for the effect of stress on risk of myocardial infarction. That is, there might be acceleration of the arteriosclerotic process resulting from the neuro-endocrine response to stress, or an interaction with hypertension. ${ }^{19}$ Alternatively, the atheroma itself might be unaltered, but stroke might be provoked by an effect on blood viscosity or coagulability. ${ }^{20}$ Either possibility is plausible, since although events are episodic in nature the severe events we studied here are defined by their propensity to exert a long-term influence on the subject's life. In our study, patients who had experienced a severe event before stroke were no more likely to have a past history of hypertension or other risk factors than were those who had not experienced such an event before their stroke, so we did not get any obvious clues as to the nature of the effect. The mechanism involved is worth pursuing, since the observation that stroke did not follow immediately upon the stressful experience raises the possibility of preventive action if mediating factors could be elucidated.
In summary, our findings provide support for the view that severely threatening life events increase the risk of stroke. Such a conclusion is in keeping with what is known about the relationship between severe events and other physical illnesses, particularly myocardial infarction, in which many of the pathological processes are similar to those underlying stroke. Before further consideration is given to possible mechanisms or the feasibility of a therapeutic intervention, it is important that this result is replicated in a different population.

This work was supported by grants from the Medical Research Council and the Chest, Heart and Stroke Association. The following departments have collaborated in the OCSP: University Department of Clinical Neurology (Dr P Sandercock, Dr J Bamford, Dr M Dennis, Dr C Warlow, Ms L Mogridge, Ms C Bamford, Dr M Dennis, Dr C Warlow, Ms L Mogridge, Ms C
Clifford, Ms S Price, Ms H Storey), Department of Neuroradiology (Dr A Molyneux, Dr P Anslow), Department of Neuroradiology (Dr A Molyneux, Dr P Anslow), Department of
Neuropathology (Dr J Hughes), University Department of Neuropathology (Dr J Hughes), University Department of Community Medicine and General Practice (Professor M
Vessey, Dr K McPherson, Dr G Fowler, Ms L Jones), Dr N Vessey, Dr K McPherson, Dr G Fowler, Ms L Jones), Dr N
Quizilbach helped with identification of the control group for Quizilbach helped with identification of the control group for
this study. General Practitioners collaborating (name of liaison this study. General Practitioners collaborating (name of liaison partner for each practice only): Dr A McPherson, Oxford; Dr A field; Dr D Otterburn, Abingdon; Dr S Street. Kidlington; Dr V Drury, Wantage; Dr R Pinches, Abingdon; Dr N Crossley, Abingdon; Dr H O'Connell, Deddington. We also thank Tirri Harris for training in the use of the LEDS and for help and advice during the study, and the independent ratings in the reliability study.

1 Ecker A. Emotional stress before strokes: a preliminary report of 20 cases. Ann Int Med 1954;40:49-56.

2 Storey P. Emotional aspects of cerebrovascular disease. $A d v$ Psychosom Med Vol 13. Basel: Karger, 1985:71-84.

3 Gentry WD, Jenkins CD, Kaplan BH, Heyman A, Breslin $\mathrm{M}$, Gianturco D. Type A behaviour pattern and ischaemic $M$, Gianturco D. Type A behaviour pattern and ischaemic
cerebrovascular disease. Heart and Lung 1979;8:1113-16. 4 Storey PB. The precipitation of subarachnoid haemorrhage. $J$ Psychosom Res 1969;13:175-82.

5 Engel GL. Sudden and rapid death during psychological stress: folklore or folk wisdom? Ann Int Med 1971;74: 771-82.

6 Penrose RJJ. Life events before subarachnoid haemorrhage. $J$ Psychoson Res 1972;16:329-33.

7 Carasso R, Yehuda S, Ben-Uriah Y. Personality type, life events and sudden cerebrovascular attack. Int $J$ Neuroscience 1981;14:223-5.

8 Brown G, Harris T. Social origins of depression. London: Tavistock, 1978.

9 Bamford J, Sandercock P, Dennis M, et al. A prospective study of cerebrovascular disease in the community: the OCSP $1981-6$.
$51: 1373-80$

10 Aho K, Harmsen P, Hatano S, Marquardsen J, Smiraov V, Strasser $T$. Cerebrovascular disease in the community: results of a WHO collaborative study. Bull WHO 1980;58:113-30

11 House A, Dennis M, Mogridge L, Warlow C, Hawton K, Jones L. Mood disorders in the first year after stroke. Brit J Psych (in press).

12 Morris J, Gardner J. Calculating confidence intervals for relative risks (odds ratios) and standardised ratios and rates. Brit Med J 1988;296:1313-16.

13 Murphy E. Social origins of depression in old age. Brit $J$ Psych 1982;141:135-42.

14 Creed F. Life events and appendicectomy. Lancet $1981 ; \mathbf{i}: 1381-5$.

15 Craig TKJ, Brown G. Goal frustration and life events in the aetiology of painful gastrointestinal disorder. $J$ Psychosom Res 1984;28:411-21.

16 Murphy E, Brown G. Life events psychiatric disturbance and physical illness. Brit J Psych 1980;136:326-38.

17 Creed F. Life events and physical illness. J Psychosom Res 1985;29:113-23.

18 Grant I, Brown G, Harris T, McDonald WI, Patterson T, Trimble $M$. Severely threatening events and marked life difficulties preceding onset or exacerbation of multiple sclerosis. J Neurol Neurosurg Psychiatry 1989;52:8-13.

19 Henry JP. Mechanisms, by which stress can lead to coronary heart disease. Postgrad Med J 1986;62:687-93.

20 Levine SP, Towell BL, Suarez AM, Knieriem LK, Harris $\mathrm{M}$, George J. Platelet activation and secretion associated with emotional stress. Circulation 1985;71:1129-34. 